\title{
Analysis of Vaginal and Endometrial Microbiota Communities in Infertile Women With a History of Repeated Implantation Failure
}

\author{
Takuhiko Ichiyama ( $\nabla$ tichiya@juntendo.ac.jp ) \\ Juntendo Daigaku https://orcid.org/0000-0003-0641-934X
}

\section{Keiji Kuroda}

Center for Reproductive Medicine and Implantation Research, Sugiyama Clinic Shinjuku

\section{Yoko Nagai}

Varinos Inc.

\section{Daichi Urushiyama}

Department of Obstetrics and Gynecology, Faculty of Medicine, Fukuoka University

\section{Motoharu Ono}

Department of Obstetrics and Gynecology, Juntendo University School of Medicine

\section{Takashi Yamaguchi}

Saint Mother Obstetrics and Gynecology Clinic and Institute for Assisted Reproductive Technologies

\section{Motoi Nagayoshi}

Saint Mother Obstetrics and Gynecology Clinic and Institute for Assisted Reproductive Technologies

\section{Yoshiyuki Sakuraba}

Varinos Inc.

\section{Fumio Yamasaki}

Division of Pathology, Japan Community Health Care Organization, Saga Central Hospital

\section{Kenichiro Hata}

Department of Maternal-Fetal Biology, National Research Institute for Child Health and Development

\section{Shingo Miyamoto}

Department of Obstetrics and Gynecology, Faculty of Medicine, Fukuoka University,

\section{Atsuo Itakura}

Department of Obstetrics and Gynecology, Juntendo University School of Medicine

\section{Satoru Takeda}

Department of Obstetrics and Gynecology, Juntendo University School of Medicine

\section{Atsushi Tanaka}

Saint Mother Obstetrics and Gynecology Clinic and Institute for Assisted Reproductive Technologies

\section{Research}


Keywords: repeated implantation failure, vagina, endometrium, microbiota, microbiome

Posted Date: September 10th, 2020

DOI: https://doi.org/10.21203/rs.3.rs-73125/v1

License: (1) (1) This work is licensed under a Creative Commons Attribution 4.0 International License. Read Full License

Version of Record: A version of this preprint was published at Reproductive Medicine and Biology on May 31st, 2021. See the published version at https://doi.org/10.1002/rmb2.12389. 


\section{Abstract}

Background: Repeated implantation failure (RIF) is estimated to occur in $15 \%-20 \%$ of infertile women undergoing in vitro fertilization-embryo transfer (IVF-ET). Molecular identification recently confirmed that the uterine microbiota may have implications for reproductive and obstetrical outcomes. One hundred forty-five women who had been diagnosed with RIF were enrolled in the study. Twenty-one healthy women were also enrolled as controls. We investigated their vaginal and endometrial microbiotas using 16S rRNA gene sequencing and compared the microbiota profiles in the patients with RIF and controls.

Results: The endometrial microbiotas had higher a-diversities than did the vaginal microbiotas $(p<0.001$ in both patients with RIF and healthy women). The microbiota profiles showed that vaginal and endometrial samples in patients with RIF had significantly higher levels of 5 and 14 bacterial genera, respectively, than those in healthy women. These genera included Atopobium, Gardnerella, Prevotella and Megasphaera. Vaginal Lactobacillus rates in patients with RIF were significantly lower at $76.4 \pm 38.9 \%$ compared with those of the controls at $91.8 \pm 22.7 \%(p=0.018)$, but endometrial Lactobacillus rates did not significantly differ between the RIF patients and controls $(56.2 \pm 36.4 \%$ and $58.8 \pm 37.0 \%$, respectively, $p=0.79$ )

Conclusions: Impaired microbiota communities containing specific bacteria in both the endometrium and vagina were associated with implantation failure. The Lactobacillus rate in the vagina, but not the endometrium, may be a biomarker for RIF.

Trial registration: UMIN Clinical Trials Registry, UMIN000031731, Registered 15 March 2018; https://upload.umin.ac.jp/cgi-open-bin/ctr_e/ctr_view.cgi?recptno=R000036121

\section{Background}

In vitro fertilization (IVF) technology and quality have rapidly advanced. Recent reports of preimplantation genetic testing for aneuploidy reported $>60 \%$ clinical pregnancy rates after embryo transfer (ET) cycles [1, 2]. However, pregnancy requires competent embryos and a receptive endometrium; therefore, repeated implantation failure (RIF) following multiple ET cycles is difficult to overcome even after IVF with euploid embryos [3].

Reproductive-related microbiota communities in women can affect reproductive and obstetric outcomes [4]. Bacterial vaginosis (BV) is associated with obstetric complications, including pregnancy loss and preterm birth [5-10]. Analyzing microbiota profiles of the amniotic fluid may help predict perinatal outcomes [11]. Moreno et al. revealed vaginal and endometrial bacterial communities from vaginal aspirates and endometrial fluid from fertile and infertile women who underwent IVF [12]. Data from the endometrial samples showed that bacterial communities from women experiencing implantation failure or pregnancy loss after ET contained more Gardnerella and Streptococcus and fewer Lactobacillus than did those from women who had successful livebirths. Furthermore, infertile patients with $>90 \%$ Lactobacillus in their endometrial microbiota (EM) had significantly good pregnancy prognoses after IVF 
than did those with $<90 \%$. Therefore, endometrial microbiome analyses are used to determine individual EM profiles in infertile women $[13,14]$. However, no study has confirmed the reproducibility of the effect of EM profiling on pregnancy outcomes after IVF. Another clinical study using EM analysis in infertile patients demonstrated that endometrial Lactobacillus ratios did not affect pregnancy outcomes after IVF $[13,14]$; therefore, evidence remains insufficient.

We focused on infertile patients with RIF histories, evaluated their vaginal and EM communities via nextgeneration sequencing, and analyzed specific RIF-associated bacteria.

\section{Methods}

The Ethical Committee of the Institutional Review Board of Saint Mother Obstetrics and Gynecology Clinic and Institute for ART, Fukuoka, Japan, approved this study in November 2017 (No.17-ST-03). The study was registered in the University Hospital Medical Information Network-Clinical Trial Registration, Japan, in March 2018 (UMIN-CTR000031731). All recruited women provided written informed consent.

We enrolled 211 consecutive women diagnosed with RIF after $\geq 3$ ET cycles using Gardner scoring system [15] grade 3BB or higher blastocysts 5-6 days post-fertilization between October 2017 and June 2018. All patients' uterine and endometrial structures were evaluated via transvaginal ultrasonography. Patients with uterine cavity ultrasounds that revealed possible causes of infertility received a diagnostic hysteroscopy to rule out intrauterine disorders (e.g., endometrial polyps, submucosal myomas, and intrauterine adhesions). Twenty-nine women were excluded after the hysteroscopy. We also excluded 30 women with other possible risk factors for reproductive failure, including 13 with thrombophilia (e.g., antiphospholipid syndrome), 15 with endocrinologic abnormalities or collagen disease, and 2 with parental chromosomal imbalances or translocations. Seven women who had received antibiotics within 1 month of sampling were excluded because antibiotics can affect microbiota communities.

Finally, 145 women were included. Forty did not provide vaginal specimens; thus, we obtained 145 endometrial samples and 105 vaginal aspirates. We also recruited 21 healthy women with etiologies of infertility because their husbands had azoospermia as the control group; these women had regular menstrual cycles without causes of infertility such as tubal factors, ovulation disorder, endometriosis, endocrinologic abnormalities, or immunological abnormalities. Figure 1 shows the participant selection methods.

\section{Vaginal and endometrial sampling}

Vaginal and endometrial samples were taken 5-7 days after ovulation or the beginning of the hightemperature phase in the basal body temperature. For women with irregular menstrual cycles, samples were taken during the hormone replacement cycle. From days $1-3$ of the menstrual cycle, 2-8 $\mathrm{mg}$ of oral estradiol valerate (Progynova ${ }^{\circledR}$, Bayer Health Care, Schering, Germany) was administered. From day 13 , oral chlormadinone acetate (8 mg; Lutoral, Shionogi, Osaka, Japan) was administered for 13 days. Samples were obtained 5-7 days after initiating oral progesterone intake. 
Vaginal discharge was collected using two sterilized swabs after placing a sterilized vaginal speculum. One swab was submitted for Nugent scoring [16], which indicates BV; the other was used to analyze the microbiota. The latter swab was immediately soaked in OMNIgene ${ }^{\circledR}$ VAGINAL (DNA Genotek Inc., Ottawa, Ontario, Canada). The vagina was then washed with physiological saline and wiped three times with dry tampons to remove vaginal secretions and cervical mucus. To minimize the risk of contaminating the endometrial samples in the vagina, a Medgyn pipette IV (Harada Corporation, Tokyo, Japan) was inserted into the uterine cavity, avoiding contact with the vaginal walls. We inserted the pipette approximately 5 $\mathrm{mm}$ from the bottom of the uterus and pulled it back toward the cervical canal under abdominal ultrasound guidance and absorbed the samples while turning the pipette slowly for 45-60 seconds. All uterine samples were placed in an in utero solution with the endometrial tissue. We stopped the absorption to prevent uptake of any cervical mucus left after washing when the pipette neared the cervix, then quickly removed the pipette from the uterus. The pipette tip was cut to $3 \mathrm{~cm}$ with sterilized surgical scissors to prevent contamination with cervical mucus. The endometrial samples were placed into the OMNIgene ${ }^{\circledR}$ VAGINAL without touching the pipette to the liquid.

\section{Evaluation of the Nugent score}

Vaginal samples were smeared on glass slides, fixed over a flame, and Gram stained. The stained slides were then examined at 1000x magnification to evaluate the Nugent scoring [16], an index for microscopically evaluating Lactobacillus, Gardnerella and Mobiluncus in vaginal samples. The scoring requires training but is a highly reproducible standard method, with scores ranging from 0 : $>30$ lactobacilli or no Gardnerella-like bacteria in the visual field to 4: no lactobacilli or $>30$ Gardnerella-like bacterium in the visual field. Mobiluncus presence is an additional 2 points. Subjects with Nugent scores of $0-3,4-6$, and $\geq 7$ points were categorized into the normal, intermediate, and BV groups, respectively.

\section{DNA extraction and 16S rRNA sequencing}

Varinos Inc., Shinagawa, Tokyo, Japan, extracted and sequenced the bacterial DNA. The vaginal and endometrial samples were treated with proteinase $\mathrm{K}$ and lysozyme solution per the manufacturer's instructions. Genomic DNA was extracted using an Agencourt Genfind v2 Blood \& Serum DNA Isolation Kit (Beckman Coulter, Inc., Miami, FL, USA) or MagNA Pure 24 (Roche Diagnostics, Grenzach-Wyhlen, Germany) Pathogen $200 \mathrm{hp} 1.0$ protocol. The dsDNA concentration was quantified fluorometrically with a Qubit dsDNA HS Assay Kit (Thermo Fisher Scientific Inc., Waltham, MA, USA). The V4 hypervariable region of the bacterial 16S rRNA gene was amplified from the specimen's DNA using the modified primer pair, $515 f$ (5'-TCG TCG GCA GCG TCA GAT GTG TAT AAG AGA CAG GTG YCA GCM GCC GCG GTA A-3') and 806rB (5'- GTC TCG TGG GCT CGG AGA TGT GTA TAA GAG ACA GGG ACT ACN VGG GTW TCT AAT3'), with Illumina Nextera XT adapter overhang sequences (underlined; Illumina, Inc., San Diego, CA, USA) [17]. PCR was performed using $25 \mathrm{ng} / \mu \mathrm{L}$ DNA, $200 \mu \mathrm{mol} / \mathrm{L}$ of each deoxynucleotide triphosphate, 400 $\mathrm{nmol} / \mathrm{L}$ of each primer, $2.5 \mathrm{U}$ FastStart HiFi polymerase, $4 \%$ of $20 \mathrm{mg} / \mathrm{mL}$ bovine serum albumin (SigmaAldrich, St. Louis, MO, USA), $0.5 \mathrm{~mol} / \mathrm{L}$ betaine (Sigma), and the appropriate buffer with $\mathrm{MgCl}_{2}$ supplied by the manufacturer (Roche Molecular Systems, Inc., Pleasanton, CA, USA). Thermal cycling consisted of 
initial denaturation at $94^{\circ} \mathrm{C}$ for 2 minutes, followed by 30 cycles of denaturation at $94^{\circ} \mathrm{C}$ for 20 seconds, annealing at $50^{\circ} \mathrm{C}$ for 30 seconds, extension at $72^{\circ} \mathrm{C}$ for 1 minute, and a final extension at $72^{\circ} \mathrm{C}$ for 5 minutes. The amplicon mixture was purified using Agencourt AMPure XP (Beckman Coulter, Inc.). Purified PCR samples were multiplexed using a dual-index approach with the Nextera XT Index kit v2 (Illumina, Inc.) per the Illumina 16S Metagenomic Sequencing Library preparation protocol. PCR indexing was performed using KAPA HiFi HotStart ReadyMix (Roche Sequencing Solutions Inc., Pleasanton, CA, USA) in a $50-\mu l$ reaction volume and subsequently purified using Agencourt AMPure XP beads. The final library was paired-end sequenced at $2 \times 200$ bp using a MiSeq Reagent Kit v3 on the Illumina MiSeq platform. The ZymoBIOMICS Microbial Community Standard (Zymo Research, Irvine, CA, USA), containing a mixture of Pseudomonas, Escherichia, Salmonella, Lactobacillus, Enterococcus, Listeria, Bacillus, and two yeast species, was used as a positive control. UltraPure ${ }^{\mathrm{TM}}$ DNase/RNase-Free Distilled Water (Thermo Fisher Scientific, Inc.) was used as a blank control.

Sequenced reads were merged using EA-Utils fastq-join [18] to obtain a 291-bp median merged sequence length. Quality control of the merged sequence was performed using USEARCH v10.0.240 [19] to remove PhiX reads, truncate primer-binding sequences, and discard sequences of $<100 \mathrm{bp}$ and with a sequence quality $<$ Q20. Quantitative Insights Into Microbial Ecology (QIIME) 1.9.1 was used with the default parameters for quality filtering, chimera checking, sequence clustering into operational taxonomic units (OTUs), and taxonomic assignment [20]. Sequences were clustered into OTUs using an open-reference OTU-picking strategy using the UCLUST method based on $97 \%$ sequence identity. Taxonomy was assigned to each OTU using RDP Classifier [21] with a 0.50 confidence threshold against the Greengenes database, version 13_8 [22].

\section{Sequencing results and OTU analysis}

Seven endometrial samples with insufficient sequence reads were excluded. Thus, 39,716,693 reads were obtained from 159 endometrial samples and 126 vaginal samples. Seven endometrial samples with $<1,000$ reads were excluded. The average read count per endometrial sample was 66,762 (range 192422,265 ) and per vaginal sample was 185,311 (range 203-611,776). After quality filtering and OTU clustering, the average read counts were 11,742 (range $551-42,236$ ) and 38,368 (range 36-46,155) for the endometrial and vaginal samples, respectively. Six endometrial samples and two vaginal samples with $<1,000$ OTU hit reads were excluded. Low-abundance taxa $(0.01 \%)$ were filtered from the OTU tables (Figure 1). Bacterial taxa in a blank control were assumed to be contaminants from various reagents; therefore, blank-characteristic taxa were subtracted to reduce background noise as in previous studies $[11,23]$. Fourteen bacterial taxa detected in a blank control and known to be reagent contaminants were excluded using QIIME: Acidovorax, Acinetobacter, Chryseobacterium, Citrobacter, Escherichia, Flavobacterium, Janthinobacterium, Leptothrix, Methylobacterium, Pseudomonas, Rhodococcus, Sphingomonas, Stenotrophomonas, and Yersinia (Table 1).

\section{$\underline{\text { Statistical analysis }}$}


We calculated the Shannon diversity index and Chao1 richness, which became the index of the microbiota's a-diversity, then conducted t-tests. We calculated the weighted UniFrac distance for analyzing the $\beta$-diversity of the microbiotas between the samples and conducted PERMANOVA tests. The tests were analyzed using QIIME 1.9.1. We performed Welch's t-tests using R 3.4.3 (https://www.r-project.org/) to compare the bacterial abundances between groups. Hierarchical analysis was performed using R 3.4.3. Distances based on the squared Euclidean distance were calculated and clustered via Ward's method.

Table 1

Microbial genera detected in blank controls.

\begin{tabular}{|lllll|}
\hline & \multicolumn{2}{l}{ Manual protocol batch $\mathbf{1}(\mathbf{n}=\mathbf{1 0})$} & \multicolumn{2}{l}{ Manual protocol batch 2 (n=14) } \\
\hline Taxonomy & $\begin{array}{l}\text { Mean } \\
\text { abundance (\%) }\end{array}$ & $\begin{array}{l}\text { Detection } \\
\text { rate }(\%)\end{array}$ & $\begin{array}{l}\text { Mean } \\
\text { abundance (\%) }\end{array}$ & $\begin{array}{l}\text { Detection } \\
\text { rate (\%) }\end{array}$ \\
\hline Pseudomonas & 20.7 & $10 / 10(100)$ & 18.9 & $14 / 14(100)$ \\
\hline Escherichia & 41.3 & $10 / 10(100)$ & 17.6 & $14 / 14(100)$ \\
\hline Rhodococcus & 2.5 & $8 / 10(80)$ & 0.1 & $1 / 14(7.1)$ \\
\hline Janthinobacterium & 2.8 & $10 / 10(100)$ & 7.4 & $13 / 14(92.9)$ \\
\hline Sphingomonas & 4.4 & $10 / 10(100)$ & 0.6 & $7 / 14(50)$ \\
\hline Flavobacterium & 3.6 & $9 / 10(90)$ & 0.8 & $12 / 14(85.7)$ \\
\hline Methylobacterium & 1.8 & $1 / 10(10)$ & 0.4 & $2 / 14(14.3)$ \\
\hline Stenotrophomonas & 2.5 & $8 / 10(80)$ & 0.6 & $9 / 14(64.3)$ \\
\hline Acinetobacter & 1.9 & $3 / 10(30)$ & 0.6 & $10 / 14(71.4)$ \\
\hline Leptothrix & 0.0 & $0 / 10(0)$ & 1.1 & $9 / 14(64.3)$ \\
\hline Acidovorax & 0.0 & $0 / 10(0)$ & 0.1 & $3 / 14(21.4)$ \\
\hline Chryseobacterium & 0.0 & $0 / 10(0)$ & 1.1 & $12 / 14(85.7)$ \\
\hline Citrobacter & 0.0 & $0 / 10(0)$ & 0.4 & $9 / 14(64.3)$ \\
\hline Yersinia & 0.0 & $0 / 10(0)$ & 48.0 & $14 / 14(100)$ \\
\hline $\begin{array}{l}\text { The composition of the bacteria detected from the blank controls varied with each lot of reagents, and } \\
\text { bacteria detected from } \text { multiple lots were used as background bacteria. }\end{array}$ & \\
\hline
\end{tabular}

\section{Results}

\section{Study_population}


Table 2 shows the demographics of the control and RIF groups. The mean ages of the RIF and control groups were $38.3 \pm 4.2$ years and $32.0 \pm 4.0$ years, respectively $(p<0.001)$. Body mass index and smoking status showed no significant differences. RIF patients had more miscarriages than did the controls; thus, gravidity in the RIF group was higher than that of the controls, yet no significant difference occurred regarding parity. Nugent scores in the control and RIF groups were $0.9 \pm 1.6$ and $1.9 \pm 2.7$, respectively. No control patient was diagnosed with BV (Nugent score $\geq 7$ ), whereas $11.9 \%$ of the RIF patients were diagnosed with BV. However, BV incidence and Nugent scores did not significantly differ $(p=0.13$ and 0.09 , respectively). Tables 3 and 4 compare the participants' characteristics for the vaginal and endometrial microbiome analyses, respectively. 
Table 2

Subjects' demographics and background characteristics.

\begin{tabular}{|c|c|c|c|}
\hline & $\begin{array}{l}\text { RIF patients }(n= \\
145)\end{array}$ & $\begin{array}{l}\text { Controls }(n= \\
21)\end{array}$ & $P$ value \\
\hline Age (years), mean $\pm S D$ & $38.3 \pm 4.2$ & $32.0 \pm 4.0$ & $0.68 \times 10^{-9}$ \\
\hline Body mass index $(\mathrm{kg} / \mathrm{m} 2)$, mean $\pm \mathrm{SD}$ & $21.1 \pm 2.8$ & $21.2 \pm 2.7$ & 0.92 \\
\hline Smoking, n (\%) & $2(1.4)$ & $1(4.8)$ & 0.28 \\
\hline \multicolumn{4}{|l|}{ Pregnancy history, mean \pm SD } \\
\hline Gravidity, mean \pm SD & $0.8 \pm 1.3$ & $0.1 \pm 0.3$ & $0.01 * b$ \\
\hline Parity, mean \pm SD & $0.1 \pm 0.3$ & 0 & 0.14 *b \\
\hline \multicolumn{4}{|l|}{ Causes of infertility, $n(\%) * a$} \\
\hline Male factor & $11(7.6)$ & $21(100.0)$ & $\begin{array}{l}0.22 \times 10^{-17} \\
{ }^{*} \mathrm{C}\end{array}$ \\
\hline Polycystic ovarian syndrome & $5(3.4)$ & 0 & $0.39{ }^{*} \mathrm{C}$ \\
\hline Endometriosis & 19(13.1) & 0 & $0.08{ }^{*} \mathrm{C}$ \\
\hline Tubal factor & $13(9.0)$ & 0 & $0.15{ }^{*} \mathrm{C}$ \\
\hline Unexplained infertility & $100(67.0)$ & 0 & $\begin{array}{l}0.41 \times 10^{-} \\
{ }^{11 *} \mathrm{C}\end{array}$ \\
\hline \multicolumn{4}{|l|}{ Previous history of ET, mean \pm SD } \\
\hline Number of cycles & $6.0 \pm 4.6$ & $0.3 \pm 0.6$ & $0.46 \otimes 10^{-7}$ \\
\hline Number of embryos transferred & $8.1 \pm 7.2$ & $0.4 \pm 0.7$ & $0.29 ه 10^{-5}$ \\
\hline Number of cycles of good embryos transferred & $3.3 \pm 2.1$ & $0.1 \pm 0.5$ & $0.34 \times 10^{-10}$ \\
\hline $\begin{array}{l}\text { Number of morphologically good embryos } \\
\text { transferred }\end{array}$ & $4.0 \pm 2.7$ & $0.1 \pm 0.5$ & $0.73 \times 10^{-9}$ \\
\hline Nugent score, mean \pm SD & $1.9 \pm 2.7$ & $0.9 \pm 1.6$ & 0.09 \\
\hline$\geq 7$ (Bacterial vaginosis), $\mathrm{n}(\%)$ & $16(11.9)$ & $0(0)$ & 0.13 \\
\hline \multicolumn{4}{|c|}{ *a. Totals do not equal $100 \%$ because some patients had more than one diagnosis. } \\
\hline \multicolumn{4}{|l|}{ *b. Student's t-test. } \\
\hline \multicolumn{4}{|l|}{${ }^{*}$ c. Fisher's exact test. } \\
\hline $\begin{array}{l}\text { Nugent score is often used for the diagnosis of } \\
\text { as the score } 7-10 \text {. }\end{array}$ & acterial vaginosis. & terial vaginosis & s diagnosed \\
\hline
\end{tabular}


Table 3

Characteristics of participants for vaginal microbiome analysis

\begin{tabular}{|c|c|c|c|}
\hline & $\begin{array}{l}\text { RIF } \\
n=103\end{array}$ & $\begin{array}{l}\text { Control } \\
n=21\end{array}$ & $p$-value \\
\hline Age (years), mean $\pm S D$ & $38.1 \pm 4.1$ & $32.0 \pm 4.0$ & $0.50 \times 10^{-8}$ \\
\hline Body mass index $(\mathrm{kg} / \mathrm{m} 2)$, mean $\pm \mathrm{SD}$ & $20.9 \pm 2.6$ & $21.2 \pm 2.7$ & 0.65 \\
\hline Smoking, n (\%) & $2(1.9)$ & $1(4.8)$ & 0.43 \\
\hline \multicolumn{4}{|l|}{ Pregnancy history, mean \pm SD } \\
\hline Gravidity, mean \pm SD & $0.7 \pm 1.2$ & $0.1 \pm 0.3$ & $0.02 * b$ \\
\hline Parity, mean \pm SD & $0.2 \pm 0.4$ & 0 & $0.08 * b$ \\
\hline \multicolumn{4}{|l|}{ Causes of infertility, $\mathrm{n}(\%){ }^{*} \mathrm{a}$} \\
\hline Male factor & $9(8.7)$ & $21(100.0)$ & $0.22 \times 10^{-15 *_{C}}$ \\
\hline Polycystic ovarian syndrome & $3(2.9)$ & 0 & $1{ }^{*} \mathrm{C}$ \\
\hline Endometriosis & 13(12.6) & 0 & $0.12{ }^{*} \mathrm{C}$ \\
\hline Tubal factor & 10(9.7) & 0 & $0.21{ }^{*} \mathrm{C}$ \\
\hline Unexplained infertility & $69(67.0)$ & 0 & $0.28 \times 10^{-8 *} \mathrm{C}$ \\
\hline \multicolumn{4}{|l|}{ Previous history of $E T$, mean \pm SD } \\
\hline Number of cycles & $5.6 \pm 4.1$ & $0.3 \pm 0.6$ & $0.37 \otimes 10^{-7}$ \\
\hline Number of embryos transferred & $7.5 \pm 6.7$ & $0.4 \pm 0.7$ & $0.42 \otimes 10^{-5}$ \\
\hline Number of cycles of good embryos transferred & $3.3 \pm 2.0$ & $0.1 \pm 0.5$ & $0.46 \times 10^{-10}$ \\
\hline Number of morphologically good embryos transferred & $3.9 \pm 2.3$ & $0.1 \pm 0.5$ & $0.10 \times 10^{-10}$ \\
\hline Nugent score, mean \pm SD & $1.9 \pm 2.7$ & $0.9 \pm 1.6$ & 0.05 \\
\hline$\geq 7$ (Bacterial vaginosis), $\mathrm{n}(\%)$ & $16(11.9)$ & $0(0)$ & 0.12 \\
\hline \multicolumn{4}{|c|}{ *a. Totals do not equal $100 \%$ because some patients had more than one diagnosis. } \\
\hline \multicolumn{4}{|c|}{ *b. Student's t-test. } \\
\hline${ }^{\star} \mathrm{C}$. Fisher's exact test. & & & \\
\hline
\end{tabular}


Table 4

Characteristics of participants for endometrial microbiome analysis

\begin{tabular}{|c|c|c|c|}
\hline & $\begin{array}{l}\text { RIF } \\
n=117\end{array}$ & $\begin{array}{l}\text { Control } \\
n=17\end{array}$ & $p$-value \\
\hline Age (years), mean $\pm S D$ & $38.0 \pm 4.2$ & $32.5 \pm 4.2$ & $0.90 \times 10^{-6}$ \\
\hline Body mass index $(\mathrm{kg} / \mathrm{m} 2)$, mean $\pm \mathrm{SD}$ & $21.3 \pm 2.9$ & $21.7 \pm 2.7$ & 0.56 \\
\hline Smoking, n (\%) & $2(1.7)$ & $0(0)$ & 1 \\
\hline \multicolumn{4}{|l|}{ Pregnancy history, mean \pm SD } \\
\hline Gravidity, mean \pm SD & $0.7 \pm 1.2$ & $0.1 \pm 0.2$ & $0.02 * b$ \\
\hline Parity, mean \pm SD & $0.2 \pm 0.4$ & 0 & $0.10 * b$ \\
\hline \multicolumn{4}{|l|}{ Causes of infertility, n (\%) *a } \\
\hline Male factor & $10(8.5)$ & 17(100.0) & $0.60 \times 10^{-14 *_{C}}$ \\
\hline Polycystic ovarian syndrome & $4(3.4)$ & 0 & $1{ }^{*} \mathrm{C}$ \\
\hline Endometriosis & $15(12.8)$ & 0 & $0.22{ }^{*} \mathrm{C}$ \\
\hline Tubal factor & $10(8.5)$ & 0 & $0.36{ }^{*} \mathrm{C}$ \\
\hline Unexplained infertility & $78(66.7)$ & 0 & $0.69 \times 10^{-7 *_{C}}$ \\
\hline \multicolumn{4}{|l|}{ Previous history of ET, mean \pm SD } \\
\hline Number of cycles & $5.8 \pm 4.1$ & $0.3 \pm 0.6$ & $0.18 \otimes 10^{-6}$ \\
\hline Number of embryos transferred & $7.8 \pm 6.8$ & $0.4 \pm 0.8$ & $0.16 \otimes 10^{-4}$ \\
\hline Number of cycles of good embryos transferred & $3.4 \pm 2.1$ & $0.1 \pm 0.5$ & $0.24 \times 10^{-8}$ \\
\hline Number of morphologically good embryos transferred & $3.9 \pm 2.6$ & $0.1 \pm 0.5$ & $0.26 \times 10^{-7}$ \\
\hline Nugent score, mean \pm SD & $2.1 \pm 2.9$ & $1.0 \pm 1.7$ & 0.14 \\
\hline$\geq 7$ (Bacterial vaginosis), $n(\%)$ & $15(12.9)$ & $0(0)$ & 0.22 \\
\hline
\end{tabular}

\section{Endometrial and vaginal microbiota bacterial diversities}

Shannon diversity and Chao 1 richness indexes as a-diversity metrics were calculated to compare the patients' vaginal and endometrial bacterial compositions (Table 5, Fig. 2A). The Shannon diversity and Chao1 richness values in 1,000 reads per sample were higher in the endometrial samples than in the vaginal samples (Shannon: $2.4 \pm 1.2$ and $0.8 \pm 0.7$, respectively, $p<0.001$; Chao1: $59.1 \pm 23.3$ and $16.9 \pm$ 10.9 , respectively, $p<0.001)$. Regarding the vaginal and endometrial samples, both the control and RIF groups had higher EM diversities (Table 5, Fig. 2B, 2C). $\beta$-diversity was analyzed to compare 
compositional dissimilarities between the EMs and vaginal microbiotas (VMs). Principal coordinate analysis ( $\mathrm{PCoA}$ ), the multivariate analysis based on weighted UniFrac distance to compare microbiome differences between groups, revealed significant associations between microbiotas ( $p=0.001$; data not shown). Interestingly, few subjects had higher uterine Lactobacillus rates than vaginal Lactobacillus rates. Most subjects with lower vaginal Lactobacillus rates also had lower endometrial Lactobacillus rates; thus, individuals with vaginal dysbiosis also had uterine dysbiosis (Fig. 3).

Table 5

Shannon index and Chao1 richness values of the microbiota derived from the identical subject.

\begin{tabular}{|llll|}
\hline & Endometrial & Vaginal & \multicolumn{1}{l|}{ P value } \\
\hline All women $(n=106)$, mean \pm SD & & \\
\hline Shannon index & $2.4 \pm 1.2$ & $0.8 \pm 0.7$ & $1.94 \times 10^{-22}$ \\
\hline Chao1 richness & $59.1 \pm 23.3$ & $16.9 \pm 10.9$ & $2.88 \times 10^{-36}$ \\
\hline Control $(n=17)$, mean \pm SD & & \\
\hline Shannon index & $2.4 \pm 1.0$ & $0.8 \pm 0.4$ & $9.49 \times 10^{-06}$ \\
\hline Chao1 richness & $60.6 \pm 18.5$ & $16.1 \pm 5.6$ & $1.34 \times 10^{-08}$ \\
\hline RIF ( $n=89)$, mean \pm SD & & $0.8 \pm 0.7$ & $4.29 \times 10^{-18}$ \\
\hline Shannon index & $2.4 \pm 1.2$ & $17.1 \pm 11.7$ & $5.61 \times 10^{-29}$ \\
\hline Chao1 richness & $58.8 \pm 24.2$ & & \\
\hline Shannon diversity and Chao1 richness were calculated based on a subsample of 1,000 sequences. \\
\hline
\end{tabular}

\section{Bacterial community differences between the RIF and control groups}

To identify the relationship between bacterial diversity and implantation failure, we compared the microbiota data from the endometrial and vaginal samples between the RIF and control groups (Table 6). The $\alpha$ - and $\beta$-diversities did not significantly differ in the EMs or VMs between the RIF and control groups (Fig. 4A and 4B). We further investigated differences between the bacterial genera in these groups. Twenty-five and 131 bacterial species were detected from the vaginal and endometrial samples, respectively. Figure 5 shows the relative bacterial abundances in the top 15 bacterial species with the highest proportions. Lactobacillus dominated in both groups and sample types. The uneven height of the bar chart for the endometrium indicates that many bacterial species other than the top 15 were detected. 
Table 6

Comparison of a-diversity between control and RIF groups

\begin{tabular}{|llll|}
\hline & RIF & Control & P value \\
\hline a-diversity of endometrial microbiota, mean \pm SD & $\mathrm{n}=117$ & $\mathrm{n}=17$ & \\
\hline Shannon index & $2.4 \pm 1.2$ & $2.4 \pm 1.0$ & 0.99 \\
\hline Chao1 richness & $59.1 \pm 22.8$ & $60.6 \pm 18.0$ & 0.8 \\
\hline a-diversity of vaginal microbiota, mean \pm SD & $\mathrm{n}=103$ & $\mathrm{n}=21$ & \\
\hline Shannon index & $0.9 \pm 0.7$ & $0.9 \pm 0.4$ & 0.99 \\
\hline Chao1 richness & $17.7 \pm 12.0$ & $16.8 \pm 6.7$ & 0.63 \\
\hline
\end{tabular}

To identify candidate bacterial genera as risk factors for RIF, bacterial abundances in the EMs and VMs were evaluated (Table 7). For bacterial species with average abundances of $>1.0 \%$, the VMs in the RIF patients had higher rates of Atopobium, Megasphaera, Gardnerella, and Prevotella than did the control group. The Lactobacillus rate in the RIF group VMs was significantly lower than that in the controls (76.4 $\pm 77.7 \%$ and $91.8 \pm 45.5 \%$, respectively, $p=0.015$ ). Of the EMs in the RIF group, 14 genera (Atopobium, Megasphaera, Gardnerella, Prevotella, Schlegelella, Delftia, Burkholderia, Sphingobacterium, Dietzia, Enterococcus, Micrococcus, Ralstonia, Leucobacter, and Hydrogenophaga) were significantly higher than those in the controls (Table 7). Surprisingly, the endometrial Lactobacillus abundances did not significantly differ between the RIF and control groups (51.2 $\pm 37.5 \%$ and $51.6 \pm 38.3 \%$, respectively). 
Table 7

Comparison of microbial genera between RIF and control groups Endometrial microbiota Vaginal microbiota

\begin{tabular}{|c|c|c|c|c|c|c|}
\hline \multirow[b]{2}{*}{$\begin{array}{l}\text { Taxonomy, \% mean } \pm \\
\text { SD }\end{array}$} & \multicolumn{3}{|c|}{ Endometrial microbiota } & \multicolumn{3}{|c|}{ Vaginal microbiota } \\
\hline & $\begin{array}{l}\text { RIF } \\
\text { patients } \\
n=117\end{array}$ & $\begin{array}{l}\text { Control } \\
n=17\end{array}$ & $\begin{array}{l}\mathrm{p}- \\
\text { value }\end{array}$ & $\begin{array}{l}\text { RIF } \\
\text { patients } \\
n=103\end{array}$ & $\begin{array}{l}\text { Control } \\
n=21\end{array}$ & $\mathrm{p}$-value \\
\hline Atopobium & $2.1 \pm 9.4$ & $0.1 \pm 0.2$ & 0.025 & $3.9 \pm 15.7$ & $0 \pm 0$ & 0.014 \\
\hline Megasphaera & $0.8 \pm 3.2$ & $0 \pm 0$ & 0.009 & $1.0 \pm 4.3$ & $0 \pm 0$ & 0.016 \\
\hline Lactobacillus & $56.2 \pm 36.4$ & $\begin{array}{l}58.8 \pm \\
37\end{array}$ & 0.794 & $76.4 \pm 38.9$ & $\begin{array}{l}91.8 \pm \\
22.7\end{array}$ & 0.018 \\
\hline Gardnerella & $5.3 \pm 16.3$ & $0.6 \pm 1.6$ & 0.003 & $10 \pm 24.2$ & $3.1 \pm 8.6$ & 0.025 \\
\hline Prevotella & $0.7 \pm 2.6$ & $0 \pm 0.1$ & 0.009 & $1.9 \pm 9.4$ & $0 \pm 0.1$ & 0.048 \\
\hline Schlegelella & $0.4 \pm 1.1$ & $0 \pm 0$ & 0.001 & - & - & - \\
\hline Delftia & $0.2 \pm 0.3$ & $0 \pm 0.1$ & 0.001 & $0 \pm 0.2$ & $0 \pm 0$ & 0.316 \\
\hline Burkholderia & $0.5 \pm 1.3$ & $0.1 \pm 0.2$ & 0.003 & - & - & - \\
\hline Sphingobacterium & $0.3 \pm 1.1$ & $0 \pm 0$ & 0.005 & - & - & - \\
\hline Dietzia & $0.1 \pm 0.5$ & $0 \pm 0$ & 0.017 & - & - & - \\
\hline Enterococcus & $0.1 \pm 0.3$ & $0 \pm 0$ & 0.025 & $0.1 \pm 0.8$ & $0 \pm 0$ & 0.316 \\
\hline Micrococcus & $0.1 \pm 0.7$ & $0 \pm 0$ & 0.033 & - & - & - \\
\hline Ralstonia & $0.3 \pm 1.2$ & $0 \pm 0.1$ & 0.034 & - & - & - \\
\hline Leucobacter & $0.2 \pm 0.6$ & $0.1 \pm 0.2$ & 0.035 & - & - & - \\
\hline Hydrogenophaga & $0.1 \pm 0.3$ & $0 \pm 0$ & 0.043 & - & - & - \\
\hline
\end{tabular}

\section{Discussion}

Although the uterus was once hypothesized to be sterile via the cervical mucus [24,25], intrauterine bacterial microbiotas have since been confirmed $[12,26,27]$. In the endometrial cells of fertile women, progesterone secretion from the luteum body induces subnuclear vacuole production, leading to increased glycogen levels [28]. Deposition of endometrial epithelial glycogen may allow bacteria to colonize the endometrium [28]. We found that the EMs had higher a-diversity than did the VMs, as previously reported [29]. Lactic acid produced by Lactobacillus acidifies the vagina, thus inhibiting the growth of other bacterial species [30,31]; however, the number of bacteria in the uterus is extremely small at $1 / 100-1 / 10,000$ that of the vagina, and some bacterial species dominate among the highly varied 
vaginal bacteria, leading to low bacterial diversity in the vagina $[32,33]$. Therefore, the EM community is mostly independent of the VM community.

The cervical mucus plug is partially impermeable to bacterial ascension from the vagina [34, 35]; therefore, some vaginal bacteria can translocate to the endometrial microenvironment. Our results demonstrated that RIF was associated with high incidences of dysbiosis, which is a microbiota community imbalance, in the both VMs and EMs compared with that of the controls. In the vagina, high Atopobium, Megasphaera, Gardnerella, and Prevotella and low Lactobacillus levels were associated with RIF. Among these genera, Atopobium, Gardnerella, Prevotella and Megasphaera have been reported as pathogenic bacteria involved in BV [36-39]. Furthermore, the reduced vaginal Lactobacillus rate can trigger pathological bacterial overgrowth in BV [36]. Therefore, vaginal dysbiosis, including BV with low Lactobacillus rates, may be a biomarker for implantation failure. Fu et al. also reported the relationship between RIF and vaginal microbial dysbiosis [40].

For the EMs, 14 bacterial genera were detected as possible risk factors for RIF. Among them, Atopobium, Gardnerella, Prevotella and Megasphaera were the same as the candidate vaginal bacteria as biomarkers for RIF; therefore, they might ascend from the vagina. Although nine other species, excluding Burkholderia, were significantly detected from the endometrial samples of RIF patients, the occupancy rate of these bacteria was $<0.5 \%$. The clinical role that these bacteria play in reproductive-aged women (excluding compromised hosts) remains unknown and requires further analysis. Kitaya et al. detected significant vaginal Burkholderia levels in RIF patients [29]; however, endometrial, but not vaginal, Burkholderia abundances differed significantly between RIF patients and controls in our study. Recently, researchers detected Burkholderia in a preterm delivery and a tubo-ovarian abscess [41, 42]; thus, Burkholderia in female reproductive organs may be associated with RIF and thus a treatment target.

Interestingly, endometrial Lactobacillus abundances did not significantly differ between RIF patients and controls. Moreno et al. reported that high Lactobacillus abundances ( $\geq 90 \%)$ in EMs were associated with good pregnancy prognoses after IVF [12]. However, in our study, only six women (28.6\%) in the control group had $\geq 90 \%$ Lactobacillus abundances in the EM. Therefore, $\geq 90 \%$ Lactobacillus abundance is not a biomarker for implantation failure. Kyono et al. reported that pregnancy outcomes after IVF in infertile patients did not significantly differ between those with and without $\geq 90 \%$ Lactobacillus in the EMs [14] A normal range for endometrial Lactobacillus rates should be reanalyzed in fertile women when reconsidering the endometrial Lactobacillus abundance as a biomarker for RIF.

Dysbiosis or BV with pathogenic bacteria (e.g., Atopobium, Megasphaera, Gardnerella and Prevotella) in the VMs may suggest endometrial dysbiosis of vaginally derived bacteria, leading to implantation failure; thus, these bacteria may be candidate biomarkers for RIF. Sampling endometrial specimens is often invasive and carries a risk of intrauterine infection, whereas collecting vaginal samples is easy and reproducible; thus, VMs yield more stable results. Some pathogenic bacteria, such as Megasphaera, are difficult to detect on common bacterial cultures [38, 39]; thus, microbiome analysis may be indispensable for patients with RIF. BV is associated with obstetric complications such as preterm birth and midterm 
abortion [5-10,43]; therefore, treating vaginal dysbiosis may help improve embryo receptivity and prevent complications post-pregnancy.

\section{Limitations}

This study had some limitations. First, the women in control group lacked the factors responsible for RIF and were controls with a high probability of being healthy and fertile but had not experienced childbirth because their husbands had azoospermia. Endometrial sampling is invasive; thus, no endometrial specimens were collected from fertile women with histories of childbirth. Second, the women in the control group were significantly younger than the infertile women who had undergone IVF in the RIF group. Although both the controls and patients with RIF were of reproductive age, bias may have occurred between the RIF and control groups owing to age-related changes in the vaginal and intrauterine environments.

\section{Conclusions}

The vaginal and endometrial environments had individual microbiota profiles. However, RIF presented high incidences of dysbiosis with Atopobium, Gardnerella, Prevotella and Megasphaera in both the VMs and EMs; therefore, vaginal dysbiosis including BV may affect endometrial microbiota communities, leading to implantation failure. In addition, vaginal, but not endometrial, Lactobacillus abundances were associated with RIF. Therefore, treating vaginal pathogenic bacteria may improve endometrial receptivity in infertile patients with histories of RIF. The vaginal microbial profiles of patients with endometrial and vaginal dysbiosis require further analysis, and treatments are needed.

\section{List Of Abbreviations}

RIF: repeated implantation failure

IVF-ET: in vitro fertilization-embryo transfer

PGT-A: preimplantation genetic testing for aneuploidy

$\mathrm{BV}$ : bacterial vaginosis

NGS: next-generation sequencing

PCoA: principal coordinates analysis

PCOS: polycystic ovary syndrome

QIIME: Quantitative Insights Into Microbial Ecology

OTUs: operational taxonomic units 


\section{Declarations}

\section{Ethics approval and consent to participate}

The Ethical Committee of the Institutional Review Board at Saint Mother Obstetrics and Gynecology Clinic and Institute for ART, Fukuoka, Japan, approved this study on November 7, 2017.

\section{Consent for publication}

Not applicable.

\section{Availability of data and materials}

All datasets supporting the results of this study are included within the article.

\section{Competing interests}

The authors declare that they have no competing interests.

\section{Funding}

JSPS KAKENHI, grant number JP18K16822, provided the financial support to interpret the data and write the manuscript.

\section{Authors' contributions}

TI, YN, DU and other members of the Saint Mother Obstetrics and Gynecology Clinic and Institute for ART conceived the study. TI, YN, DU and YS oversaw and contributed to the data collection and participated in writing and reviewing the manuscript. YN and YS developed the low-biomass 16S rRNA amplicon sequencing method, analyzed the data and wrote the paper. All authors read and approved the final manuscript.

\section{Acknowledgments}

The authors thank the women who participated in the study and acknowledge the contributions and support of Mr. Tanaka and Ms. Fukagawa at the information center of Saint Mother Obstetrics and Gynecology Clinic and Institute for ART. The authors thank Traci Raley, MS, ELS, from Edanz Group (https://en-author-services.edanzgroup.com/ac) for editing a draft of this manuscript.

\section{Authors' information (optional)}

\section{References}

1. Capalbo A, Rienzi L, Cimadomo D, Maggiulli R, Elliott T, Wright G, et al. Correlation between standard blastocyst morphology, euploidy and implantation: an observational study in two centers involving 
956 screened blastocysts. Hum Reprod. 2014;29:1173-81

2. Orvieto R. Preimplantation genetic screening- the required RCT that has not yet been carried out. Reprod Biol Endocrinol. 2016;14:35

3. Margalioth EJ, Ben-Chetrit A, Gal M, Eldar-Geva T. Investigation and treatment of repeated implantation failure following IVF-ET. Hum Reprod. 2006;21:3036-43

4. Salim R, Ben-Shlomo I, Colodner R, Keness Y, Shalev E. Bacterial colonization of the uterine cervix and success rate in assisted reproduction: results of a prospective survey. Hum Reprod. 2002;17:33740

5. Romero R, Hassan SS, Gajer P, Tarca AL, Fadrosh DW, Nikita L, et al. The composition and stability of the vaginal microbiota of normal pregnant women is different from that of non-pregnant women. Microbiome. 2014;2:4

6. Ravel J, Gajer P, Abdo Z, Schneider GM, Koenig SS, McCulle SL, et al. Vaginal microbiome of reproductive-age women. Proc Natl Acad Sci U S A. 2011;108 Suppl 1:4680-7

7. Romero R, Hassan SS, Gajer P, Tarca AL, Fadrosh DW, Bieda J, et al. The vaginal microbiota of pregnant women who subsequently have spontaneous preterm labor and delivery and those with a normal delivery at term. Microbiome. 2014;2:18

8. Ralph SG, Rutherford AJ, Wilson JD. Influence of bacterial vaginosis on conception and miscarriage in the first trimester: cohort study. BMJ. 1999;319:220-3

9. Hay PE, Lamont RF, Taylor-Robinson D, Morgan DJ, Ison C, Pearson J. Abnormal bacterial colonisation of the genital tract and subsequent preterm delivery and late miscarriage. BMJ. 1994;308:295-8

10. Romero R, Chaiworapongsa T, Kuivaniemi H, Tromp G. Bacterial vaginosis, the inflammatory response and the risk of preterm birth: a role for genetic epidemiology in the prevention of preterm birth. Am J Obstet Gynecol. 2004;190:1509-19

11. Urushiyama D, Suda W, Ohnishi E, Araki R, Kiyoshima C, Kurakazu M, et al. Microbiome profile of the amniotic fluid as a predictive biomarker of perinatal outcome. Sci Rep. 2017;7:12171

12. Moreno I, Codoner FM, Vilella F, Valbuena D, Martinez-Blanch JF, Jimenez-Almazan J, et al. Evidence that the endometrial microbiota has an effect on implantation success or failure. Am J Obstet Gynecol. 2016;215:684-703

13. Franasiak JM, Werner MD, Juneau CR, Tao X, Landis J, Zhan Y, et al. Endometrial microbiome at the time of embryo transfer: next-generation sequencing of the $16 \mathrm{~S}$ ribosomal subunit. J Assist Reprod Genet. 2016;33:129-36

14. Kyono K, Hashimoto T, Kikuchi S, Nagai Y, Sakuraba Y. A pilot study and case reports on endometrial microbiota and pregnancy outcome: An analysis using 16S rRNA gene sequencing among IVF patients, and trial therapeutic intervention for dysbiotic endometrium. Reprod Med Biol. 2019;18:7282

15. Gardner DK, Lane M, Stevens J, Schlenker T, Schoolcraft WB. Reprint of: Blastocyst score affects implantation and pregnancy outcome: towards a single blastocyst transfer. Fertil Steril. 
2019;112:e81-e4

16. Nugent RP KM, Hillier SL. Reliability of diagnosing bacterial vaginosis is improved by a standardized method of gram stain interpretation. J Clin Microbiol. 1991;29:297-301

17. Walters W, Hyde ER, Berg-Lyons D, Ackermann G, Humphrey G, Parada A, et al. Improved Bacterial 16S rRNA Gene (V4 and V4-5) and Fungal Internal Transcribed Spacer Marker Gene Primers for Microbial Community Surveys. mSystems. 2016;1:e00009-15

18. Aronesty E. Comparison of Sequencing Utility Programs. The Open Bioinformatics Journal. 2013;7:18

19. Edgar RC, Haas BJ, Clemente JC, Quince C, Knight R. UCHIME improves sensitivity and speed of chimera detection. Bioinformatics. 2011;27:2194-200

20. Caporaso JG, Kuczynski J, Stombaugh J, Bittinger K, Bushman FD, Costello EK, et al. QIIME allows analysis of high-throughput community sequencing data. Nat Methods. 2010;7:335-6

21. Wang Q, Garrity GM, Tiedje JM, Cole JR. Naive Bayesian classifier for rapid assignment of rRNA sequences into the new bacterial taxonomy. Appl Environ Microbiol. 2007;73:5261-7

22. McDonald D, Price MN, Goodrich J, Nawrocki EP, DeSantis TZ, Probst A, et al. An improved Greengenes taxonomy with explicit ranks for ecological and evolutionary analyses of bacteria and archaea. ISME J. 2012;6:610-8

23. Salter SJ, Cox MJ, Turek EM, Calus ST, Cookson WO, Moffatt MF, et al. Reagent and laboratory contamination can critically impact sequence-based microbiome analyses. BMC Biology. 2014;12

24. Romero R, Espinoza J, Mazor M. Can endometrial infection/inflammation explain implantation failure, spontaneous abortion, and preterm birth after in vitro fertilization? Fertil Steril. 2004;82:799804

25. Moller BR, Kristiansen FV, Thorsen P, Frost L, Mogensen SC. Sterility of the uterine cavity. Acta Obstet Gynecol Scand. 1995;74:216-9

26. Baker JM, Chase DM, Herbst-Kralovetz MM. Uterine Microbiota: Residents, Tourists, or Invaders? Front Immunol. 2018;9:208

27. Moreno I, Simon C. Relevance of assessing the uterine microbiota in infertility. Fertil Steril. 2018;110:337-43

28. Toda S, Ando H, Nagasaka T, Tsukahara S, Nomura M, Kotani Y, et al. Existence of placental leucine aminopeptidase/oxytocinase/insulin-regulated membrane aminopeptidase in human endometrial epithelial cells. J Clin Endocrinol Metab. 2002;87:1384-9

29. Kitaya K, Nagai Y, Arai W, Sakuraba Y, Ishikawa T. Characterization of Microbiota in Endometrial Fluid and Vaginal Secretions in Infertile Women with Repeated Implantation Failure. Mediators Inflamm. 2019;2019:4893437

30. Aagaard K, Ma J, Antony KM, Ganu R, Petrosino J, Versalovic J. The placenta harbors a unique microbiome. Sci Transl Med. 2014;6:237ra65 
31. Aagaard K, Riehle K, Ma J, Segata N, Mistretta TA, Coarfa C, et al. A metagenomic approach to characterization of the vaginal microbiome signature in pregnancy. PLoS One. 2012;7:e36466

32. Chen C, Song X, Wei W, Zhong H, Dai J, Lan Z, et al. The microbiota continuum along the female reproductive tract and its relation to uterine-related diseases. Nat Commun. 2017;8:875

33. Mitchell CM, Haick A, Nkwopara E, Garcia R, Rendi M, Agnew K, et al. Colonization of the upper genital tract by vaginal bacterial species in nonpregnant women. Am J Obstet Gynecol. 2015;212:611 e1-9

34. Kunz G, Beil D, Deiniger H, Einspanier A, Mall G, Leyendecker G. The uterine peristaltic pump - Normal and impeded sperm transport within the female genital tract. Fate of the Male Germ Cell. 1997;424:267-77

35. Hansen LK, Becher N, Bastholm S, Glavind J, Ramsing M, Kim CJ, et al. The cervical mucus plug inhibits, but does not block, the passage of ascending bacteria from the vagina during pregnancy. Acta Obstet Gynecol Scand. 2014;93:102-8

36. Machado A, Cerca N. Influence of Biofilm Formation by Gardnerella vaginalis and Other Anaerobes on Bacterial Vaginosis. J Infect Dis. 2015;212:1856-61

37. Balkus JE, Srinivasan S, Anzala O, Kimani J, Andac C, Schwebke J, et al. Impact of Periodic Presumptive Treatment for Bacterial Vaginosis on the Vaginal Microbiome among Women Participating in the Preventing Vaginal Infections Trial. J Infect Dis. 2017;215:723-31

38. Elovitz MA, Gajer P, Riis V, Brown AG, Humphrys MS, Holm JB, et al. Cervicovaginal microbiota and local immune response modulate the risk of spontaneous preterm delivery. Nat Commun. 2019;10:1305

39. Fettweis JM, Serrano MG, Brooks JP, Edwards DJ, Girerd PH, Parikh HI, et al. The vaginal microbiome and preterm birth. Nat Med. 2019;25:1012-21

40. Fu M, Zhang X, Liang Y, Lin S, Qian W, Fan S. Alterations in Vaginal Microbiota and Associated Metabolome in Women with Recurrent Implantation Failure. mBio. 2020;11

41. Baka S, Dramountani M, Karachalios C, Michaliadis I, Kouskouni E, Panoulis K. Case report of a potential association between Burkholderia cepacia and preterm delivery of a twin pregnancy following in vitro fertilization. Int J Gynaecol Obstet. 2018;140:121-2

42. Nernsai P, Sophonsritsuk A, Lertvikool S, Jinawath A, Chitasombat MN. A case report of Tubo-ovarian abscess caused by Burkholderia pseudomallei. BMC Infect Dis. 2018;18:73

43. Leitich $\mathrm{H}$, Bodner-Adler B, Brunbauer M, Kaider A, Egarter C, Husslein P. Bacterial vaginosis as a risk factor for preterm delivery: a meta-analysis. Am J Obstet Gynecol. 2003;189:139-47

\section{Figures}




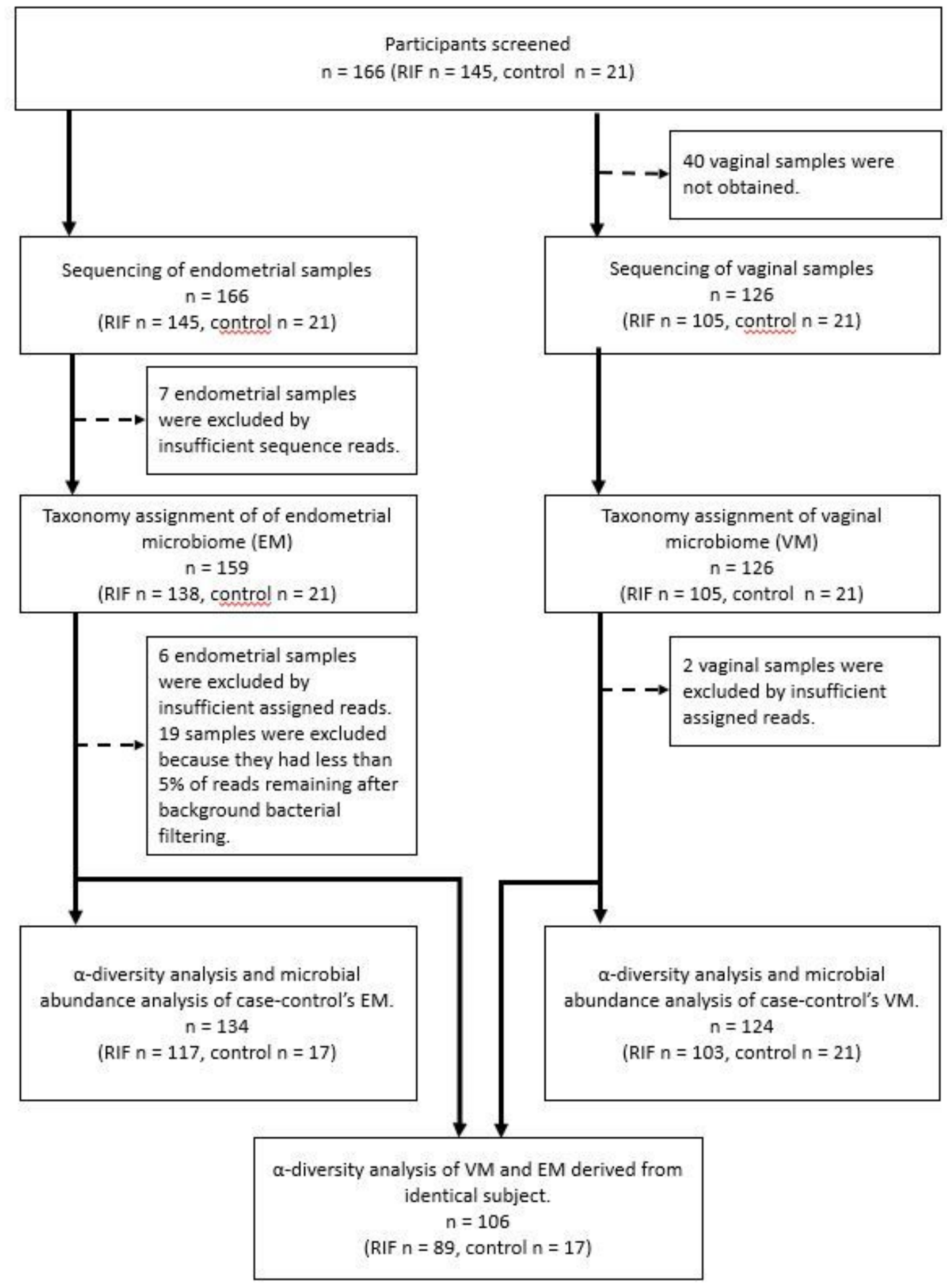

Figure 1

\section{Figure 1}

Study flowchart of the participants. Subsequent selection methods are shown. 
A
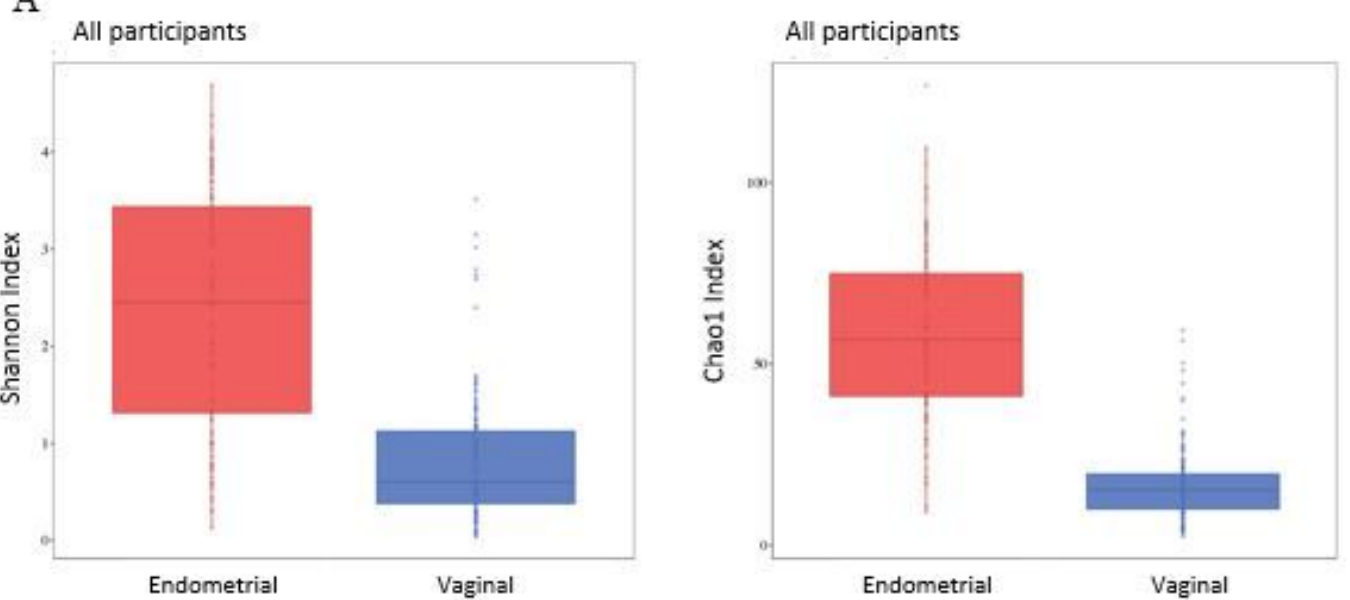

B
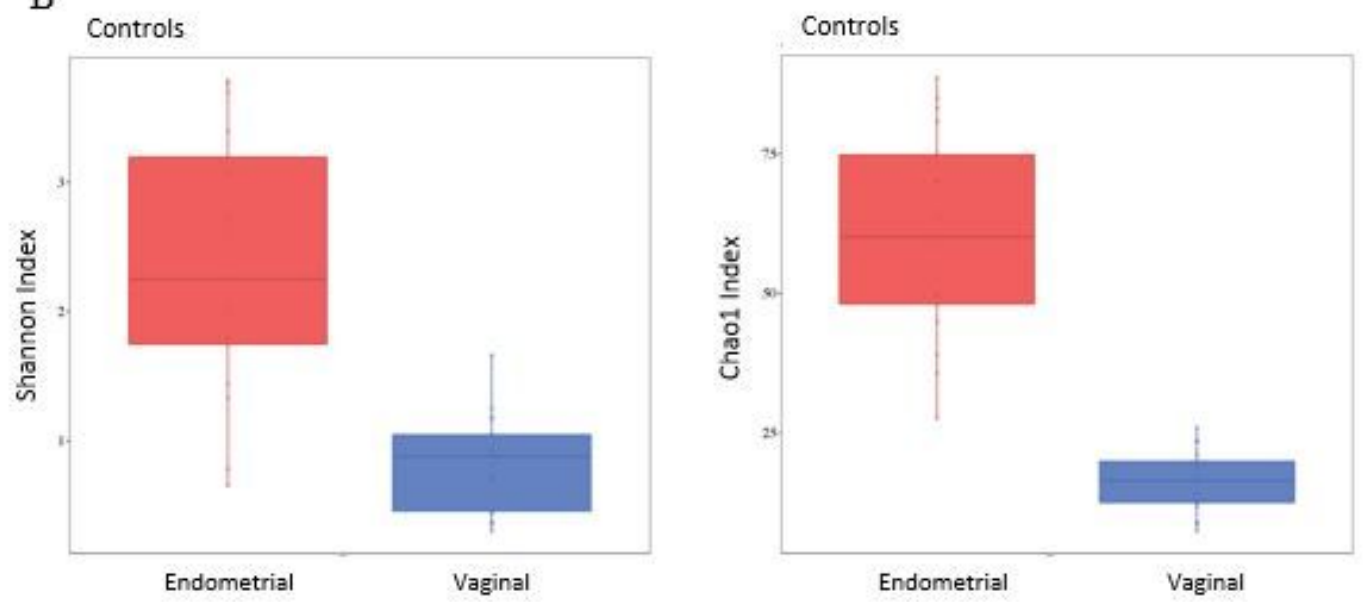

$\mathrm{C}$
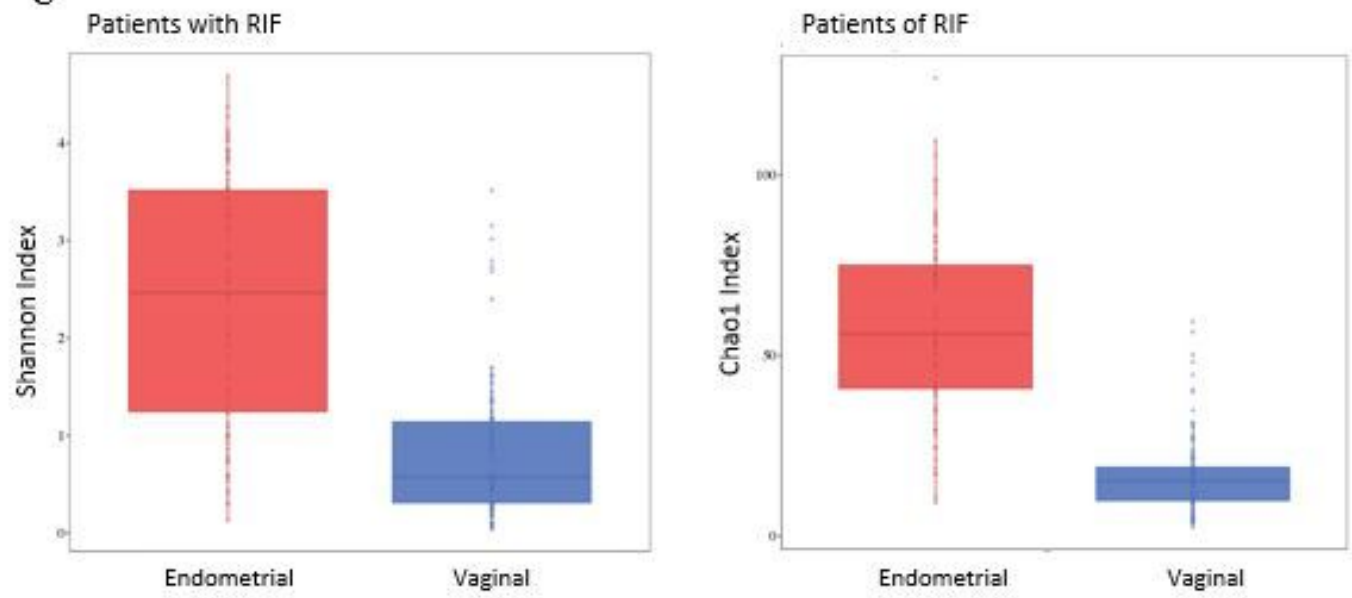

Figure 2

Figure 2

a-diversities of the endometrial and vaginal bacterial compositions. Shannon diversity and Chao1 richness of the endometrial and vaginal microbiotas were calculated from the same individual from all participants (A), the controls (B) and RIF patients (C). 


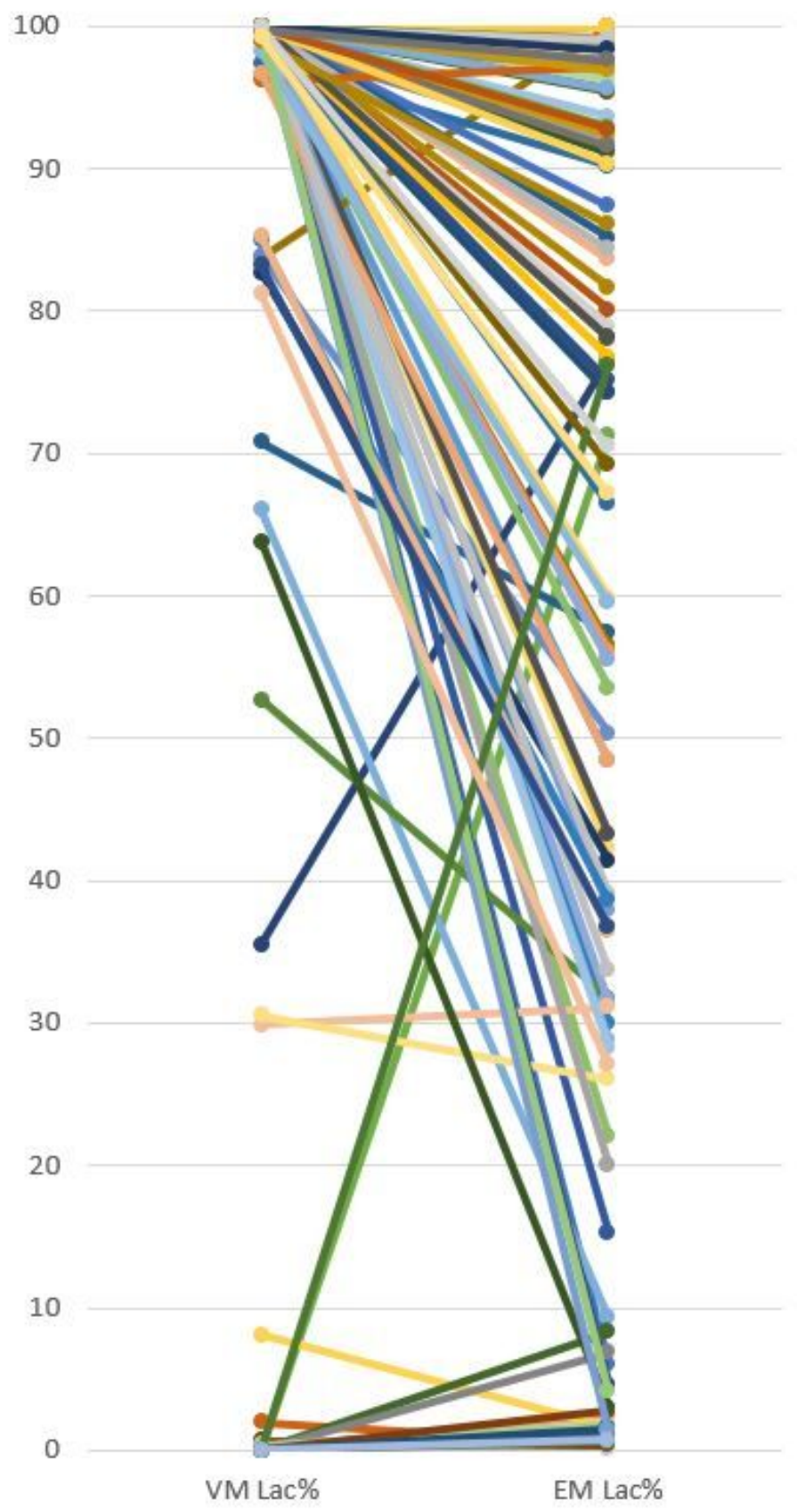

Figure 3

\section{Figure 3}

Comparison of Lactobacillus rates between vaginal and endometrial microbiotas from the same subject. From the 106 participants who provided both vaginal and endometrial samples, most (74 subjects) had a Lactobacillus-rich vaginal microbiota (Lac\% $\geq 90 \%$ ). Thirty-two of 74 subjects $(43.2 \%)$ had vaginal and endometrial Lactobacillus rates that were both $\geq 90 \%$. Conversely, $31 / 32$ subjects $(96.9 \%)$ had vaginal and endometrial Lactobacillus rates of $\leq 90 \%$. 
A

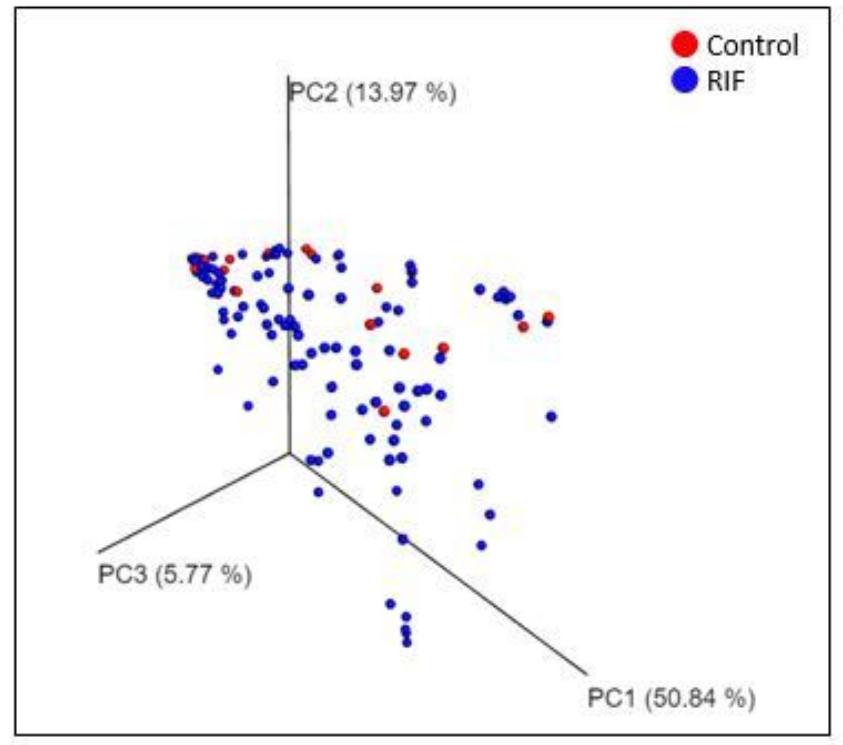

Endometrial microbiota
B

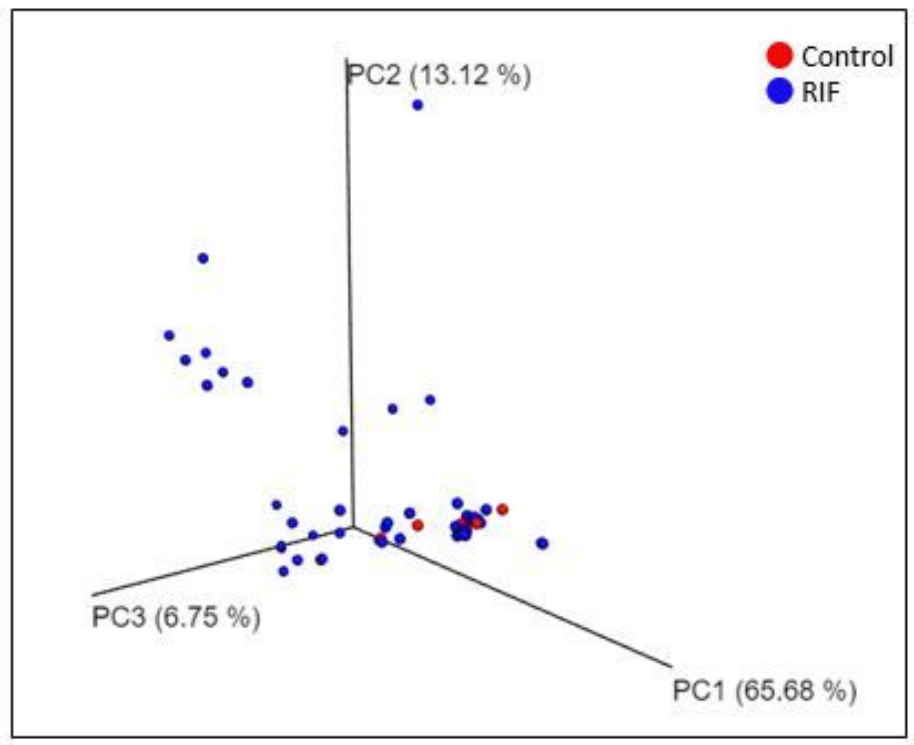

Vaginal microbiota

\section{Figure 4}

\section{Figure 4}

PCoA plot showing the relationship between the bacterial compositions of the controls and RIF patients. (A) PCoA plot based on weighted UniFrac distance representing the endometrial microbiotas of the controls (red) and RIF patients (blue). A PERMANOVA test was conducted to compare the $\beta$-diversity between the controls and RIF patients $(p=0.30)$. (B) PCoA plot based on the weighted UniFrac distance representing the vaginal microbiota $(p=0.053)$. 


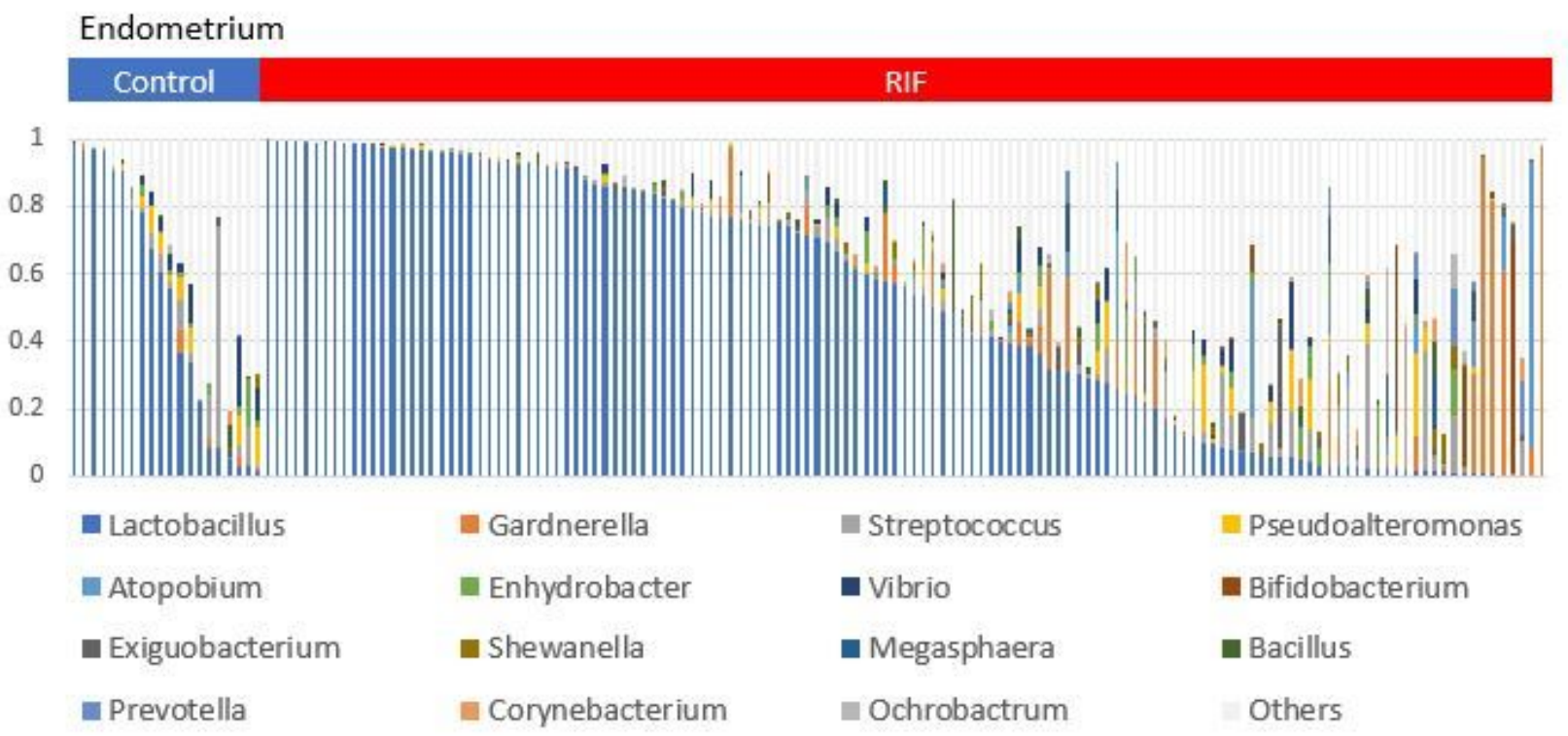

B

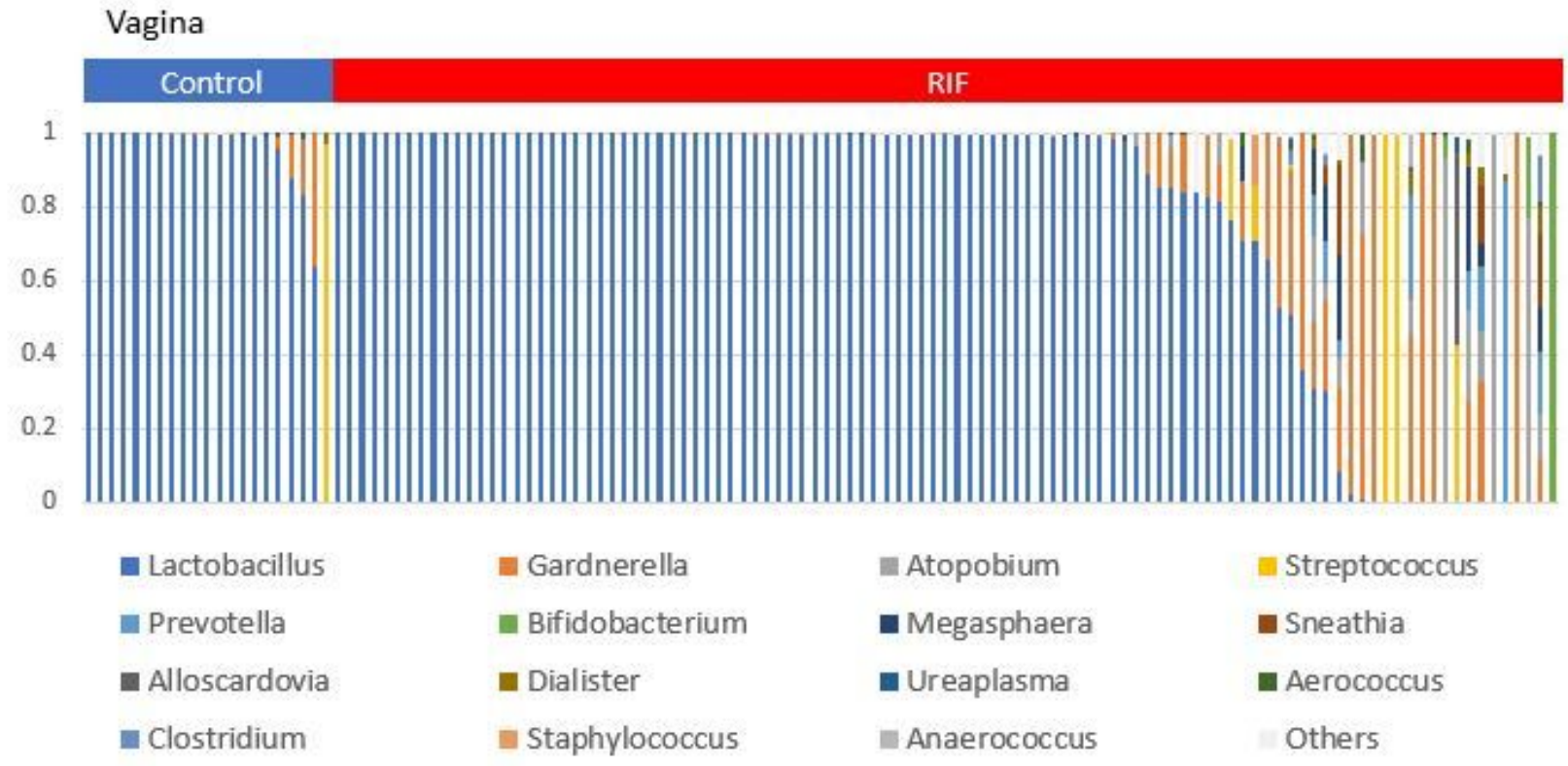

Figure 5

Figure 5

Bar charts of the bacterial species compositions in the vaginal and endometrial microbiotas of 166 participants. Endometrial (A) and vaginal (B) microbiotas. Twenty-five bacterial species were detected from the vagina, and 131 were detected from the uterus. The top 15 bacterial species are displayed. One bar on the horizontal axis represents one sample. The vertical axis represents the bacterial abundance in the microbiota. 